\title{
Bilateral Renal Cortical Necrosis with Chronic Renal Failure as a Result of Placenta Percreta in a Twin Pregnancy - A Case Report
}

\author{
Bilaterale Nierenrindennekrose mit chronischer Niereninsuffizienz als Folge \\ einer Placenta percreta bei Geminischwangerschaft - ein Fallbericht
}

Authors

Affiliation

\author{
A. Biener, N. Klünder
}

Frauenklinik, Klinikum Stuttgart, Stuttgart

\section{Key words}

- twin pregnancy

- placenta praevia

- placenta percreta

- renal failure

Schlüsselwörter

- Mehrlingsschwangerschaft

- Placenta praevia

- Placenta percreta

- Niereninsuffizienz

\begin{abstract}
received 7.8.2012
revised 27.9.2012

accepted 14.10.2012
\end{abstract}

\section{Bibliography}

DOI http://dx.doi.org/

10.1055/s-0032-1327941

Geburtsh Frauenheilk 2012; 72 :

1033-1035 @ Georg Thieme

Verlag KG Stuttgart · New York ISSN 0016-5751

\section{Correspondence}

\section{Dr. Andrea Biener}

Klinikum Stuttgart

Frauenklinik

Prießnitzweg 24

70374 Stuttgart

a.biener@klinikum-stuttgart.de

\section{Abstract \\ $\nabla$}

A 22-year-old gravida II, para I, with a twin pregnancy was diagnosed with placenta praevia totalis et percreta in $25 \mathrm{GW}$. After consideration of various modes of delivery a C-section was performed with retention of the placenta percreta in situ when vaginal bleeding occured in $28 \mathrm{GW}$. Following 8 dosages of methotrexate given on an outpatient basis, the patient suddenly developed acute renal failure necessitating dialysis. This was due to a bilateral renal cortical necrosis after disseminated intravasal coagulation based on a massive accumulation of trophoblastic tissue.

\section{Introduction}

$\nabla$

We report here on an unusual case of placenta percreta. Placentation disorders (placenta accreta, increta, and percreta) occur in around $2 \%$ of all births [1]. The incidence of placenta percreta reported in the literature ranges between 1:7000 [2] and $1: 2500$ [3] pregnancies. Due to increasing numbers of C-sections, however, over the last few years the incidence appears to be on the rise.

After a diagnosis of placenta percreta has been made ante partum, there are four main approaches for clinical management:

1. C-section with hysterectomy

2. Planned in situ retention of the placenta percreta with embolisation of the uterine artery

3. Planned in situ retention of the placenta percreta with subsequent methotrexate therapy

4. Planned in situ retention of the placenta percreta with expectant management and close monitoring

The main criterion for conservative management of placenta percreta is the wish of the patient to

\section{Zusammenfassung \\ $\nabla$}

Bei einer 22-jährigen II.-Gravida, I.-Para mit Geminigravidität wurde in der 25. SSW eine Placenta praevia totalis et percreta diagnostiziert. Nach Abwägung verschiedener Entbindungsmodi wurde bei vaginaler Blutung in der 28. SSW eine Sectio mit Belassen beider Zwillingsplazenten in situ durchgeführt. Im Anschluss an 8 ambulante Zyklen Methotrexat i.m. entwickelte die Patientin plötzlich eine Niereninsuffizienz mit Dialysepflichtigkeit. Diese kam durch eine bilaterale Nierenrindennekrose in Folge einer ausgeprägten disseminierten intravasalen Gerinnung aufgrund einer massiven Trophoblasteinschwemmung zustande.

have more children [1]. Moreover, in cases of placenta percreta with invasion of the bladder, conservative management results in fewer operative complications, such as fistula formation or injury to the ureter, both of which are associated with high maternal morbidity [3]. Complications of conservative management of placenta percreta described in the literature include bleeding, infection (endometritis, wound infection, peritonitis, pyelonephritis, uterine necrosis), sepsis and septic shock, fistula formation, thrombosis, pulmonary embolism, pulmonary oedema, and the side-effects of methotrexate therapy [3]. Acute renal failure has only been described in one case with methotrexate injection into the umbilical cord and was considered an acute side-effect of methotrexate therapy [3]. In a systematic review done in 2011, the course in 434 patients with placenta accreta, increta, and percreta treated with conservative therapy was investigated. Severe vaginal bleeding occurred in $53 \%$ of cases and sepsis in $6 \%$; the secondary hysterectomy rate was $19 \%$ ( $6 \%$ in patients treated with methotrexate), and maternal mortality was $0.3 \%(0-4 \%)$. 
$67 \%$ of patients managed conservatively became pregnant again [1].

\section{Case Report \\ $\nabla$}

A 22-year-old gravida II, para I, with a previous history of secondary $\mathrm{C}$-section and repeat pregnancy in rapid succession, presented with a dichorial diamniotic twin pregnancy and was diagnosed with placenta praevia totalis in the 21st gestational week (GW). The patient was admitted to our hospital in the $24+1 \mathrm{GW}$ with acute vaginal bleeding. In addition to placenta praevia totalis, sonographic imaging was suspicious for placenta percreta of the 1 st twin with the placenta of the 2nd twin immediately adjacent on the uterine wall (๑ Fig. 1). This suspicion was confirmed by cystoscopy. During the patient's stay in hospital, various modes of delivery including C-section followed by hysterectomy or retention of the placenta percreta in situ followed by methotrexate therapy were discussed with the patient and her partner. Based on the overall combination of findings they opted to leave the placenta percreta in situ with subsequent methotrexate therapy.

After the recurrence of vaginal bleeding and the onset of labour, secondary C-section was performed in the $27+2 \mathrm{GW}$ and the twin placenta were left in situ. As the placenta of the 2nd twin was directly adjacent to the placenta percreta, it was considered too risky to remove the 2 nd placenta. Two preterm infants were delivered, in differing stages of growth. Both adapted well and continued to develop according to their stage of maturation. The patient received 2 units of packed red blood cells perioperatively together with prophylactic antibiosis consisting of cefuroxime administered intravenously. On the 1st postoperative day, methotrexate therapy with the dosage tailored to the patient's weight ( $76 \mathrm{mg}=50 \mathrm{mg} / \mathrm{m}^{2}$ median BSA) was initiated. Different therapy regimes for methotrexate dosages and application to treat placenta percreta have been described in the literature $[2,4,5]$. The above dosage chosen by us and the application interval had previously been used successfully in another patient with placenta percreta treated in our hospital and corresponded to dosages given in the British therapy guidelines for the conservative management of tubal pregnancy [6]. On the 13th postoperative day, the patient was discharged home in good general health with further monitoring done on an outpatient basis.

The patient continued to receive a weekly application of methotrexate at the dosages described above; each after routine laboratory investigations such as complete blood count, CRP, and creatinine levels. The patient received a total of $8 \times 76 \mathrm{mg}$ doses of methotrexate administered intramuscularly. Throughout this period, levels of $\beta$-HCG were controlled regularly and the patient was monitored with regular sonograms. Initially, vascularisation of the placenta praevia and percreta regressed well, but as levels

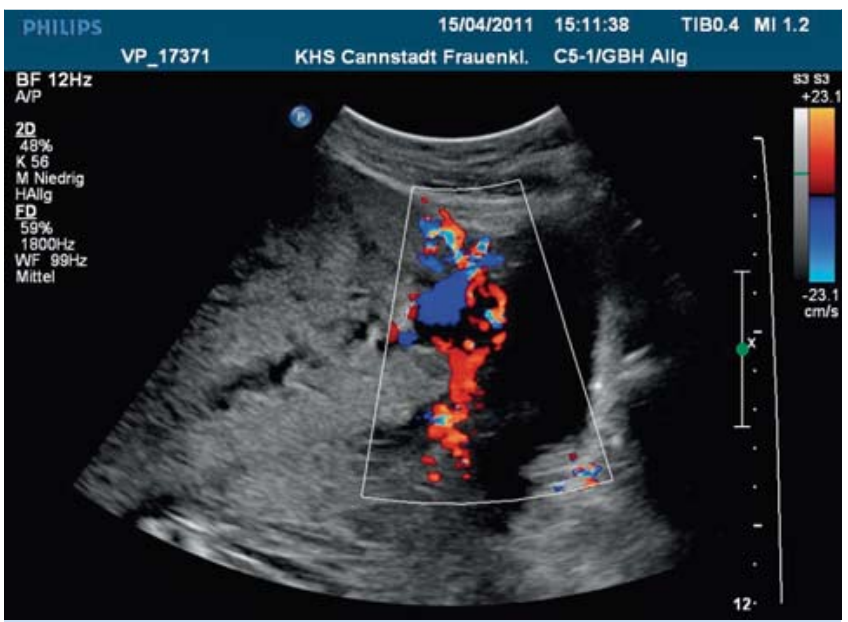

Fig. 1 Sonographic imaging of placenta praevia totalis et percreta in our patient.

of $\beta$-HCG in serum stagnated, vascularisation began to increase again ( Table 1 ).

The patient was readmitted to hospital 4 days after the last administration of methotrexate with moderate vaginal bleeding and impaired coagulation (Quick's value: 56\%, partial thromboplastin time [PTT]: $36 \mathrm{~s}$ ). After a brief time in the intensive care unit where the bleeding was stopped and coagulation parameters improved, the patient was initially transferred to the general ward again, and conservative management of the placenta percreta still appeared possible. Three days later, however, there was strong clinical deterioration with renal failure necessitating dialysis (creatinine increase from $0.5 \mathrm{mg} / \mathrm{dl}$ on admission to $3.4 \mathrm{mg} / \mathrm{dl}$ after a few days), and incipient pulmonary oedema. The patient also presented with intermittent accompanying symptoms such as diarrhoea, vomiting, icterus, and pancytopenia. After the patient was stabilised in the intensive care unit, secondary hysterectomy was performed with reconstruction of the bladder. Intraoperatively, the patient required mass transfusion and the administration of coagulation factors. Two days after the operation, the patient was transferred to the nephrological intensive care unit for further treatment. Due to the pulmonary oedema she required ventilation for 10 more days. She continued to be anuric and required dialysis.

Subsequently, comprehensive differential diagnostics were done. Based on the accompanying gastrointestinal symptoms described above and the pancytopenia, there was an initial suspicion that the acute renal failure was a consequence of methotrexate intoxication. But the serum methotrexate levels were already below the detection limit a few days after administration of the last dose; moreover, the overall low dosages administered (one

Table 1 Course of laboratory findings during methotrexate therapy.

\begin{tabular}{|c|c|c|c|c|c|c|c|c|}
\hline & 2011-04-21 & $2011-04-28$ & 2011-05-05 & 2011-05-12 & 2011-05-19 & 2011-05-26 & 2011-06-03 & 2011-06-10 \\
\hline $\mathrm{Hb}(\mathrm{g} / \mathrm{dl})$ & 9.2 & 7.0 & 10.5 & 10.1 & 10.0 & 10.7 & 11.4 & 10.7 \\
\hline Quick (\%) & 100 & $>110$ & & & & & & \\
\hline PTT (s) & 31 & 29 & & & & & & \\
\hline CRP (mg/dl) & 16.5 & 3.7 & 1.3 & 1.8 & & 2.3 & 2.5 & 1.8 \\
\hline Crea (mg/dl) & 0.7 & 0.6 & & & 0.4 & 0.6 & 0.6 & 0.7 \\
\hline$\beta$-HCG (IU/I) & 60212 & 22155 & 20975 & 7612 & 3893 & 1422 & 649 & 674 \\
\hline
\end{tabular}


tenth of the dosage administered in tumour therapies) and subsequent unremarkable bone marrow aspiration militated against an overdose of methotrexate. Hypovolaemic shock as the cause of acute renal failure appeared unlikely, as vaginal bleeding was quickly stopped after admission to hospital, and the patient's vital parameters remained unremarkable until she required intubation. Sepsis was excluded based on the constantly stable CRP levels and negative procalcitonin. Haemolytic-uraemic syndrome (HUS) was excluded because of the rapid increase in thrombocytes after the administration of thrombocyte concentrates and the too low numbers of schistocytes; similarly, EHEC and hantavirus serology found no pathogens. Massive preeclampsia was also discussed as a possible cause but was excluded from the differential diagnosis due to the fact that the patient's blood pressure remained normal, she had no proteinuria and the sFlt/PlGF ratio was unremarkable.

Further diagnostic imaging finally showed bilateral necrosis of the renal cortex on MRT as the cause of the existing renal failure. Based on laboratory findings, which showed a fibrinogen level of $<50$ at the time of the dramatic clinical deterioration, the assumption was that pronounced disseminated intravasal coagulation was the cause of the bilateral renal cortical damage. This was most probably triggered by a massive accumulation of trophoblastic tissue from the twin placentas remaining in situ at the time of the recurrence of vaginal bleeding. It is known that extensive necrosis of the renal cortex can occur as a result of a thrombosis of the interlobular artery and the afferent vessels, particularly after an endotoxic shock (in our case through the accumulation of trophoblasts) with disseminated intravasal coagulation [7]. As this pathomechanism appeared to be the most plausible one, the nephrologists in attendance decided against performing invasive renal biopsy.

One year after renal failure the patient permanently requires dialysis and is on the list for kidney transplantation.

\section{Discussion}

\section{$\nabla$}

A case like the one presented here of placenta percreta with bilateral renal cortical damage and subsequent chronic renal failure has not been previously described in the literature. We therefore suggest that careful evaluation and detailed diagnostics are important if placenta percreta is left in situ. The infiltration of adjacent organs, the wish of the mother to have more children, and the special course in cases with twin placentas with large amounts of trophoblastic material are all important points to watch. If conservative management is chosen post partum, frequent and regular sonographic monitoring together with monitoring of coagulation parameters and renal function is required.

\section{Conflict of Interest}

$\nabla$

None.

\section{References}

1 Steins Bisschop CN, Schaap TP, Vogelvang TE et al. Invasive placentation and uterus preserving treatment modalities: a systematic review. Arch Gynecol Obstet 2011; 284: 491-502

2 Henrich W, Fuchs I, Ehrenstein T et al. Antenatal diagnosis of placenta percreta with planned in situ retention and methotrexate therapy in a woman infected with HIV. Ultrasound Obstet Gynecol 2002; 20: 90-93

3 Sentilhes L, Ambroselli C, Kayem G et al. Maternal outcome after conservative treatment of placenta accreta. Obstet Gynecol 2010; 115: 526534

4 Mussalli G, Shah J, Berck DJ et al. Placenta accreta and methotrexate therapy: three case reports. J Perinatol 2000; 5: 331-334

5 Nijman RGW, Mantingh A, Aarnoudse JG. Persistent retained placenta percreta: methotrexate treatment and Doppler flow characteristics. BJOG 2002; 109: 587-588

6 Royal College of Obstetricians and Gynaecologists. The management of tubal pregnancy. 2004, reviewed 2010. Guideline No.21. www.rcog. org.uk/files/rcog-corp/GTG21_230611.pdf

7 Wetzels E, Buchwald M, Herms W et al. Bilateral renal cortical necrosis. Dtsch Med Wochenschr 1963; 88: 2073-2081

Deutschsprachige Zusatzinformationen online abrufbar unter: www.thieme-connect.de/ejournals/toc/gebfra. 